\title{
国家公园游憩功能的实现 武夷山国家公园试点区游客生态系统服务需求和支付意愿
}

\author{
何思源 ${ }^{1}$, 苏 杨 $^{2}$, 王 ${ }^{\text {蕾 }}{ }^{3}$, 程红光 ${ }^{4}$ \\ (1. 中国科学院地理科学与资源研究所, 北京 $100101 ; 2$. 国务院发展研究中心管理世界杂志社, 北京 100013; \\ 3. 世界自然基金会(瑞士)北京代表处,北京 100037;4. 北京师范大学环境学院,北京 100875)
}

\begin{abstract}
摘要: 引人生态系统服务概念, 考察游客作为生态系统服务关键受益人对武夷山国家公园试 点区可以提供的生态系统服务作何选择, 并对其投资自然资本保障生态系统服务的支付意愿 进行初步分析, 探讨国家公园试点建设中如何优化旅游, 促进保护和公益性功能实现。研究结 果显示: (1)游客以文化服务为首选, 主要体现在实践性强的生态旅游、较为抽象的文化体验以 及较为单纯的美景欣赏三方面, 在生态旅游具体需求上会出现选择间的相互竞争; (2)除了净 化空气, 对供给服务和其他调节服务则需求不大; (3)在免门票假设下, 具有支付意愿的游客达 到 90\%以上, 然而平均支付意愿没有达到现有门票价格; (4)教育水平和职业对支付意愿的影 响最为显著, 并与年龄和收人等因子一起形成具有不同支付意愿上的特征人群。因此, 武夷山 国家公园体制试点建设中, 需要积极探索协同多种文化服务供给, 大力推动社会参与理念, 从 根本上提高受益者对生态系统的认知, 从受益者需求人手推进国家公园公益性功能的实现。
\end{abstract}

关键词：国家公园;生态系统服务;支付意愿;武夷山

国家公园理念从 19 世纪末的美国发展至今，在全球经历了概念本土化和标准国际化 的双重过程。在国际化的过程中，世界自然保护联盟（IUCN）将国家公园归为 6 类保护 地之一（第 II 类）, 这一分类系统提供的是概念而非法律层面的定义, 其管理也不存在标 准模式。因此，在概念本土化过程中，不同国家可以从自身的保护地体系和制度变迁人 手开展保护地体系构建和管理，使其发挥功效。国家公园理念的现代视角立足于生态系 统管理, 重视生态系统价值, 依赖于生态科学和系统规划, 重视原住民和本地居民附着 于自然物之上的文化价值。这一理念，在全球范围内得到了不断地实践和改进 ${ }^{[1]}$ 。

基于生态系统的管理关键在于确保生态系统有能力长期提供多样化的服务来促进人 类福祉 ${ }^{[2]}$ 。当前, 中国开始逐步推进国家公园体制建设, 希望以国家公园来保护大规模生 态系统的原真性、完整性并实现多样化的功能。这一理念联结生态系统的自然本底与人 类需求, 正是以生态系统管理为目标。因此, 研究如何在国家公园中保障生态系统服 务，可以支持基于生态系统管理的实践需要。

在历史视角下，国家公园的建立目的和管理目标经历了巨大变化，人们认为国家公 园和其他大型保护区可以作为区域发展的工具，旅游业在其中成为减小环境代价、支持 自然保育、宣传本土文化的重要支柱 ${ }^{[3]}$; 旅游者本身, 也成为生态系统服务的关键受益

收稿日期：2018-08-10；修订日期：2018-11-21

基金项目：世界自然基金会吕克・霍夫曼研究员项目；国家社会科学基金重大项目（14ZDB142）

作者简介：何思源 (1984- ), 女, 山西太原人, 博士, 主要从事生态系统服务、社会一生态系统动态和保护地管理 研究。E-mail: hesy@igsnrr.ac.cn 
人。因此, 在生态系统服务框架下研究旅游, 不仅因为它是文化服务的一部分, 而且在 于旅游管理对于实现国家公园 “保护为主，全民公益性优先” 的目标至关重要。不少研 究发现, 旅游活动会给保护地生物多样性和生态系统完整性带来影响 ${ }^{[4-6]}$ 。近年来, 有些 学者对旅游相关的文化服务供给从游客认知的角度出发进行识别和制图研究, 揭示了游 頽功能实现的关键地带和形式, 为土地利用规划和生态系统管理提供科学依据 ${ }^{[7-8]}$ 。相对 而言, 从利益相关者社会选择的角度来进行生态系统服务重要性评估的研究在国内还比 较少 ${ }^{[9-11]}$ ，对于生态系统服务供需匹配的整体性研究还在探索中 ${ }^{[12]}$ 。

对于不同生态系统服务和产品，需要根据其产品属性，考虑政府、市场和非政府机 构的多方参与以达到最有效的供给 ${ }^{[1-15]}$ 。国家公园本身是一个公共资源，但是从产品的经 济属性上来看, 具体的生态系统服务可以具有多元化的商品属性（私有、公共池塘和公 共产品等)。因此，国家公园需要同时进行非营利性管理和营利性经营 ${ }^{[1] 6}$; 在非营利性管 理时，需要充分调动公众参与，帮助降低管理成本，支持公益性的可持续 ${ }^{[17]}$ 。

对于保护事业的公益性，研究发现游客对生物多样性和环境保护的支付意愿反映了 游客对于生物多样性和生态系统服务的成本一收益价值评估, 包含了他们对保护地正外 部性的认可程度，对公益性的支持程度，以及保护地对于满足游客特定生态服务需求， 特别是与游憩相关的需求的重要性 ${ }^{[18-19]}$ 。目前, 虽然在国家公园试点区范围内有基于游憩 目的地的旅游价值评估 ${ }^{[20]}$, 但尚未从游客认知和社会选择的角度开展生态系统服务重要 性评估, 并将其与生态保护支付意愿相关联。对武夷山地区的生态系统服务研究主要集 中在对自然保护区和风景名胜区的多样化生态系统服务价值评估上 ${ }^{[2-23]}$, 以数值相对量和 时间变化来体现生态系统服务的重要性和供给动态，但是没有从生态系统服务受益者的 社会选择出发, 较少考虑生态服务供需匹配, 也没有考虑空间上生态系统的连续和完 整，难以为国家公园管理的机制设计提供足够的信息。

因此，本文聚焦武夷山国家公园试点区依托的风景名胜区内游客，提出以下假设： 通过了解游客对生态系统服务的选择和支付意愿, 可以确定国家公园内旅游业开展所需 重视和保障的关键生态系统商品和服务, 根据游客为保障生态系统服务流量而保护自然 资本的意愿, 形成有针对性的管理方法以保障生态系统服务供给。研究旨在了解：(1) 游客作为关键生态系统服务受益人之一对武夷山地区生态系统服务做出何种选择; (2) 为保护生态系统完整性, 游客对武夷山地区保护事业的支持以及国家公园公益性的实现 持何种态度。

\section{1 研究方法与数据来源}

\section{1 研究区概况}

国家公园试点区总面积 $982.59 \mathrm{~km}^{2}$, 包括武夷山国家级风景名胜区 $64 \mathrm{~km}^{2}$, 武夷山 国家级自然保护区 $565.27 \mathrm{~km}^{2}$ 和九曲溪生态保护区 $353.32 \mathrm{~km}^{2}$, 后者含九曲溪光倒刺鲃国 家级水产种质资源保护区 $12 \mathrm{~km}^{2}$ 和武夷山国家森林公园 $74.18 \mathrm{~km}^{2}$ (图 1)。

试点区保证了九曲溪流域生态系统完整性, 包含了中亚热带原生性森林生态系统植 被垂直带谱, 囊括了丰富的物种和地貌, 是对原有保护地生态破碎化空间的重新整合, 也涉及到原有国家级自然保护区管理局、风景名胜区管理委员会、地方政府及林业、住 建、水利、文化、旅游等主管部门的协调。其中, 武夷山风景名胜区管理委员会成立近 


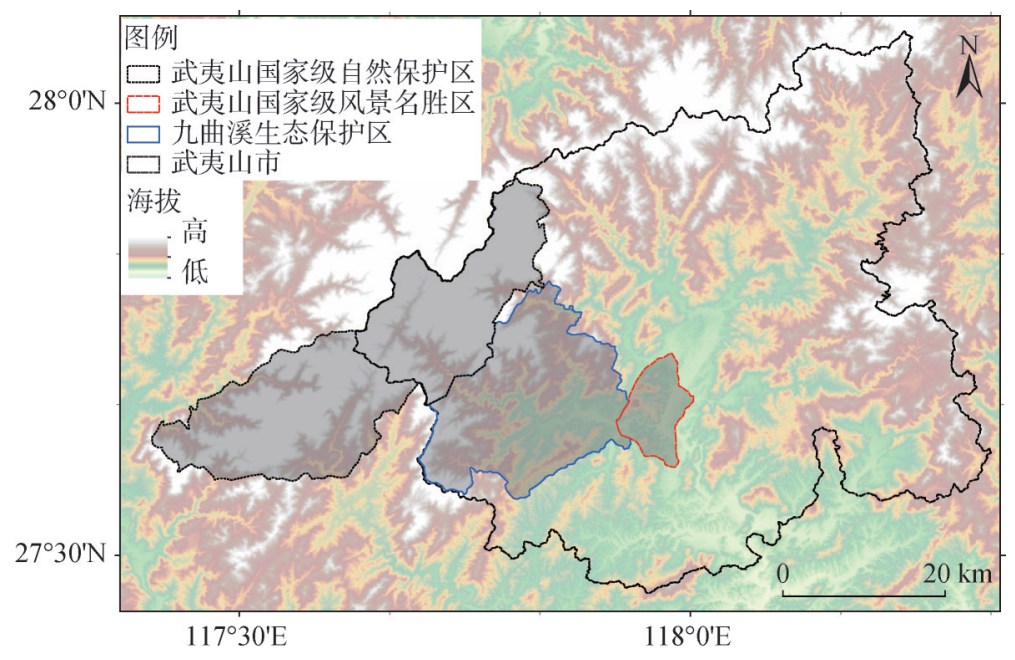

图 1 武夷山国家公园体制试点区位置（阴影部分）、组成和与武夷山市的地理关系 ${ }^{[24]}$

Fig. 1 The location and composition of the Wuyishan national park pilot (in shadow)

35 年, 景区知名度高, 管理较为成熟, 是目前也是未来国家公园分区管理中的主要开放 空间 ${ }^{[24]}$ 。2015 年，武夷山风景名胜区（主景区）接待游客 342.84 万人次 ${ }^{[25]}$, 景区门票、 竹筏专营权收人和资源保护费估计达到 10828 万元 ${ }^{[26]}$ 。

\section{2 研究方法}

\subsection{1 问卷和量化}

研究以问卷调查为主要方式。调查问卷分为四部分：（1）调查对象基本信息, 涉及 性别、年龄、教育水平、个人年收人、地区、职业等六方面人口统计特征信息。（2）两 个涉及到保护意识预判的因素，即是否亲身参加过环境类的公益活动，是否对国家公园 概念有一定了解。（3）游客对国家公园具体生态系统服务的选择和排序; 生态系统服务 类型基于新千年评估分为大项和小项 ${ }^{[27]}$ ，涵盖了除 “支持服务” 外的其他三类生态系统 服务, 小项共 41 个, 是针对武夷山（森林）生态系统的细化, 来自既往研究 ${ }^{[1-13]}$ 、实地 预调查以及学者讨论; 小项配有图片以辅助受访者理解生态系统服务, 受访者需要从 13 个大项里选择 5 个自己最为需要的并按照重要程度从 1 排到 5 , 并进一步从所选 5 大项中 分别选择小项 1 2个。(4) 以免门票为前提, 考察游客对保护的支付意愿（Willingness to pay, WTP ), 提问游客每人每次进人武夷山国家公园愿意支付多少资金（三日内多次 不限)。目前武夷山国家级风景名胜区主景区与观光车三日联票费用为 255 元, 设计为支 持国家公园保护工作而自愿付费区间共 6 档，分别为 $0 、 0 \sim 50 、 50 \sim 100 、 100 \sim 200 、 200 \sim$ 400 以及 400 以上（单位：元/人次）。

\subsection{2 调研和抽样}

研究人员于 2016 年7 月 25-31 日在武夷山国家级风景名胜区主景区进行随机抽样, 共 发放、回收问卷 398 份，其中有效问卷 394 份，有效率为 $99.0 \%$ 。生态系统服务存在时间 变化, 但考虑到游客出行高峰且研究针对游客的社会选择, 在这一时段取得的信息具有 时间和行业代表性。问卷调查对象的人口统计学信息如表 1 所示。调查员与受访者采用 一对一形式对国家公园概念、中国国家公园体制试点进程和武夷山国家公园试点区建设 
等进行必要的解释，在不进行主观引导的情况下保证受访者理解调查目的和问卷问题。

在整体样本中（表 1)，调查对象性别比例大致均衡; 年龄构成以具有较高经济能力 的 25 60 岁群体为主（共计 63.2\%); 文化水平以高中以上为主（共计 $85.53 \%$ ), 大学以 上学历达到 $63.96 \%$; 个人年收人集中在 10 万元以下（共计 $86.3 \%$ ); 游客来源以东部地 区为主，福建本省达到样本总量的 $38 \%$ ，南平市和武夷山市分别占总量的 $9 \%$ 和 $16 \%$ 。样 本涵盖的职业类型广泛，学生群体（包括大专院校）最大，专业技术人员（工程师、教 师、医疗人员）和政府工作人员群体比例相对较高（共计 $30.21 \%$ ）。保护地背景认知表 明，样本中参与过环保志愿活动的 (192，41.88\%）少于未参加过的 (202，58.12\%); 听说或去过国家公园的人数 $(268 ， 68.02 \%)$ 是否定回答人数 $(126 ， 31.98 \%)$ 的两倍。

表 1 调查对象人口统计学特征

Table 1 Demographic characteristics of the interviewees

\begin{tabular}{|c|c|c|c|c|c|c|c|}
\hline 项目 & 类别 & 样本量/个 & 百分比 $/ \%$ & 项目 & 类别 & 样本量/个 & 百分比 $/ \%$ \\
\hline \multirow[t]{2}{*}{ 性别 } & 1 男 & 192 & 48.73 & 地区 & 1 东部 & 282 & 71.57 \\
\hline & 2 女 & 202 & 51.27 & & 2 中部 & 59 & 14.97 \\
\hline \multirow[t]{5}{*}{ 年龄 } & $1<18$ 岁 & 52 & 13.20 & & 3 西部 & 46 & 11.68 \\
\hline & 2 18 25 岁 & 80 & 20.30 & & 4 其他 ${ }^{*}$ & 7 & 1.78 \\
\hline & 3 25 40 岁 & 139 & 35.28 & 职业 & 1 政府工作人员 & 25 & 6.35 \\
\hline & 4 40 60 岁 & 110 & 27.92 & & 2 企业管理人员 & 40 & 10.15 \\
\hline & $5>60$ 岁 & 13 & 3.30 & & 3 工程师/教师/医疗人员 & 94 & 23.86 \\
\hline \multirow[t]{5}{*}{ 教育水平 } & 1 小学及以下 & 16 & 4.06 & & 4 服务/销售人员 & 37 & 9.39 \\
\hline & 2 初中 & 41 & 10.41 & & 5 工人 & 11 & 2.79 \\
\hline & 3 高中 & 85 & 21.57 & & 6 农民 & 5 & 1.27 \\
\hline & 4 大学 & 219 & 55.58 & & 7 学生 & 105 & 26.65 \\
\hline & 5 研究生及以上 & 33 & 8.38 & & 8 军人** & 1 & 0.25 \\
\hline \multirow[t]{5}{*}{ 年收人 } & $1<1$ 万元 & 132 & 33.50 & & 9 离退休人员 & 12 & 3.05 \\
\hline & 21 万 5 万元 & 112 & 28.43 & & 10 个体户 & 24 & 6.09 \\
\hline & 35 万 10 万元 & 96 & 24.37 & & 11 其他 & 40 & 10.15 \\
\hline & $4>10$ 万元 & 54 & 13.71 & & & & \\
\hline & & & & 总计 & & 394 & \\
\hline
\end{tabular}

注：“代表香港：2, 台湾：4, 新加坡：1, 共7个地区没有纳人统计分析; “代表军人职业没有纳人统计分析。

\subsection{3 数据分析}

本文对问卷中的选择排序问题采用加权打分法，每种生态系统服务被选为 1 5 位的 排位被分别赋予 5 至 1 的 5 个得分，未被选择则为 0 分，记为 $S_{i}$, 分别对应一个选择频率 $f_{i}$, 从而得到参与排序的 13 个大项的各自得分, $\sum_{i=1}^{n=6} S_{i} \times f_{i}$; 小项得分由综合大项排位和小 项选择频率得到; 采用置信度为 0.05 水平的卡方检验对支付意愿选择是否受到人口统计 学因素影响进行检验；对支付意愿的影响因素进行多重对应分析（MCA） ${ }^{[28]}$ 和最优尺度 回归。对支付意愿具体金额计算依据算术平均值估计方法，以 WTP 投标区间中值和区间 选择人数分布频率，平均值 $\left(E_{W T P}\right)$ 为下限值和上限值的平均。其中下限值为 $E\left(W T P_{l}\right)=\sum P_{i} \times B_{i}$, 上限值计算时认为游客选择上一区段的比例为该区段比例 $E\left(W T P_{h}\right)=$ 
$\sum P_{i-1} \times B_{i}$, 其中 $E$ 为支付意愿期望值; $P_{i}$ 为选择该支付意愿金额人数的分布频率; $B_{i}$ 为 支付意愿金额; $n$ 为可供选择的支付意愿选项数 ${ }^{[29]}$ 。

\section{2 结果分析}

\section{1 重要生态系统产品和服务选择}

在列出的 13 项生态系统服务大项中，排在前五的第一位是生态旅游，其次是净化空 气、本土文化、美学价值和环境教育（表 2), 每一项基本都被 50\%以上的受访者选人过 前五项。除净化空气是调节服务外，其他都是文化服务。从受益尺度上看，除净化空气 的生态效应可以超越生态系统所在地, 其他都基本上只为到达一定地域范围内的人群所 享受。净化空气作为森林生态系统的主要调节功能之一, 尽管与气候、水分和土壤调节 的空间尺度类似，但其好处可以被游客短期内直接感受。其他调节服务，以及农林产品 等供给服务游客基本不会选择。

与整体评价做对比，可以发现游客来源的地域空间差异对生态服务重要性评估存在 影响。从得分来看，来自东、中、西部以及港澳台和国外的四类游客都将生态旅游排在 首位。净化空气在大陆游客的评估中都排在第二, 而在非大陆游客的评估中是第五。本 土文化在东、中部游客评估结果中仍然是第三, 而西部游客认为森林气候调节作用更为 重要, 将本土文化排在第五, 港澳台游客则将本土文化排到第二; 美学价值在三组人群 里都排在第四，但在西部游客的评估中未进人前五; 环境教育在东、中部游客评估结果 中仍然是第五，在西部游客评估中是第四，在非大陆游客评估中是第三。

同时考虑 13 个大项排序和 41 个小项的选择，可以得到排名在前 $20 \%$ 的 8 个具体生态 系统服务, 下文中括号内为小项/大项内小项总数所在大项。排名首位的是充足的氧气

表 2 游客对武夷山地区生态系统服务的选择和排序

Table 2 Preference and ranking of ecosystem services by tourists of Wuyishan

\begin{tabular}{|c|c|c|c|c|c|c|c|c|}
\hline \multirow{2}{*}{ 生态系统服务" } & \multicolumn{6}{|c|}{ 排序选择频率 } & \multirow{2}{*}{ 得分 } & \multirow{2}{*}{ 顺序 } \\
\hline & 1 & 2 & 3 & 4 & 5 & 未选 & & \\
\hline 生态旅游" & 0.51 & 0.12 & 0.11 & 0.07 & 0.07 & 0.12 & 3.57 & 1 \\
\hline 净化空气** & 0.13 & 0.23 & 0.13 & 0.07 & 0.08 & 0.36 & 2.20 & 2 \\
\hline 本土文化 & 0.06 & 0.11 & 0.16 & 0.19 & 0.10 & 0.39 & 1.69 & 3 \\
\hline 美学价值" & 0.06 & 0.10 & 0.12 & 0.13 & 0.12 & 0.47 & 1.43 & 4 \\
\hline 环境教育" & 0.05 & 0.07 & 0.11 & 0.10 & 0.17 & 0.51 & 1.23 & 5 \\
\hline 气候调节"* & 0.06 & 0.08 & 0.08 & 0.07 & 0.07 & 0.64 & 1.06 & 6 \\
\hline 经济作物 ${ }^{* * *}$ & 0.03 & 0.10 & 0.06 & 0.09 & 0.11 & 0.61 & 1.02 & 7 \\
\hline 淡水 ${ }^{* * * *}$ & 0.03 & 0.06 & 0.05 & 0.05 & 0.06 & 0.76 & 0.68 & 8 \\
\hline 森林采集*** & 0.01 & 0.06 & 0.06 & 0.08 & 0.05 & 0.74 & 0.67 & 9 \\
\hline 水分调节"* & 0.01 & 0.03 & 0.03 & 0.06 & 0.05 & 0.81 & 0.45 & 10 \\
\hline 科学研究 & 0.02 & 0.02 & 0.03 & 0.04 & 0.08 & 0.81 & 0.41 & 11 \\
\hline 土壤调节"* & 0.01 & 0.01 & 0.03 & 0.03 & 0.01 & 0.91 & 0.26 & 12 \\
\hline 水稻种植 ${ }^{* * *}$ & 0.01 & 0.02 & 0.02 & 0.02 & 0.01 & 0.94 & 0.18 & 13 \\
\hline 木材*** & 0.01 & 0.01 & 0.01 & 0.02 & 0.03 & 0.93 & 0.15 & 14 \\
\hline
\end{tabular}

注：“"”、“分别表示文化服务、调节服务、供给服务。 
( $1 / 2$ 净化空气 $)$, 其次是竹筏游览 ( $1 / 6$ 生态旅游 $) 、$ 茶文化 $(1 / 5$ 本土文化)、森林疗养

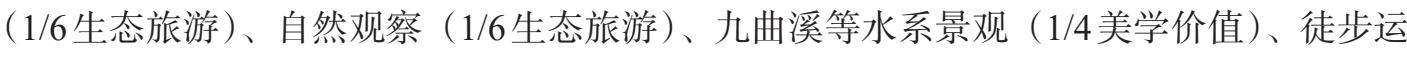
动 $(1 / 6$ 生态旅游 $)$ 以及参与式活动 $(1 / 4$ 环境教育 $)$ 。 8 个小项均来自排名前五的大项，生 态旅游小项达到 4 个，其余 4 个则分别来自另外 4 个大项。大项排名第一的生态旅游中民 宿和茶园体验相对需求较小，排名 10 位之后; 净化空气中另一小项减小风沙排在第 9 ; 本土文化里茶文化需求明显，其他 4 项涉及宗教、考古和农业文化的均在 10 位之后; 美 学价值里水景受到青睐, 丹霞地貌排在第 10 , 其余两项自然和人工植被景观均在 10 位之 后; 环境教育中，通过印刷物、博物馆和解说进行教育等三项都排在 15 位之后。

对前 8 项关键生态系统服务选择进行多重对应分析，结果的三个主成分对生态系统 服务的具体社会需求的解释率达到 50.03\%（表 3)。第一主成分以生态旅游的竹筏、徒 步、森林疗养和自然观察等需求为主，但 是前两者与后两者表现出选择上的权衡 (分别为正值和负值); 第二主成分以作为 本土文化之一的茶文化和环境教育中的参 与式活动的协同为主 (均为负值); 第三主 成分以美学价值的水景为主。三个主成分 基本代表了实践性强的生态旅游、较为抽 象的文化体验以及较为单纯的美景欣赏。

\section{2 公益费用支付意愿}

调查中个别游客明确认为国家公园免 除门票在当前国情下难以施行, 会造成地 方财政损失或其他旅游配套涨价; 不过, 样本整体表现出自愿支付费用支持保护生 态这一给全民带来正外部性的事业（表 4）。9\%的人表示不愿意支付任何费用, 在 其余 5 个选择区间中，50 100 元/人次和 100 200 元/人次两个选项选择频率远高于 其他选项，整个样本支付意愿在选项区间

\section{表 3 生态系统服务需求间的协同和权衡}

Table 3 Synergy and trade-off between ecosystem services demand

\begin{tabular}{lccc}
\hline 生态系统服务 & \multicolumn{3}{c}{ 因子得分 } \\
\cline { 2 - 4 } & $F 1$ & $F 2$ & $F 3$ \\
\hline 调节服务 & & & \\
$\quad$ 充足的氧气 & 0.399 & 0.156 & -0.382 \\
文化服务 & & & \\
$\quad$ 竹筏 & 0.716 & 0.027 & 0.422 \\
茶文化 & -0.119 & -0.569 & 0.504 \\
森林疗养 & -0.588 & -0.073 & 0.358 \\
自然观察 & -0.926 & -0.218 & -0.310 \\
九曲溪水景 & 0.009 & 0.663 & 0.880 \\
$\quad$ 徒步 & 0.752 & -0.574 & -0.001 \\
参与式活动 & 0.282 & -0.938 & -0.141 \\
特征值 & 1.424 & 1.154 & 1.109 \\
惯量解释率/\% & 17.803 & 14.426 & 13.857 \\
惯量累计解释率/\% & 17.803 & 32.229 & 50.032 \\
\hline
\end{tabular}
内呈倒 “ $U$ ” 形变化特征，对未知政策选择时显得保守和中庸。受访者平均支付意愿为 165.9 元/人次，是一日游票价的 $80 \%$ 。实际访问时，大部分受访者认为支付应当是一次 性的，即在短期内无论进人景区多少次，支付一次即可。考虑到目前武夷山风景名胜区 主景区 2015 年接待量 (342.84万人次), 在不考虑国家公园试点区功能区规划调整且认 为多数游客要进人景区 3 次以上, 则接受免门票而进行公益支付的总额可以达到 1.8 亿

表 4 受访者免门票后公益费用支付意愿分布表

Table 4 The distribution of the WTP by tourists under the hypothesis of entry fee waiver

\begin{tabular}{ccccccc}
\hline 支付选项/元/人次 & 0 & $<50$ & $50 \sim 100$ & $100 \sim 200$ & $200 \sim 400$ & $>400$ \\
\hline 样本量 & 37 & 63 & 134 & 102 & 39 & 19 \\
频率/\% & 9 & 16 & 34 & 26 & 10 & 5 \\
支付选项编号 & 1 & 2 & 3 & 4 & 5 & 6 \\
\hline
\end{tabular}


元，而武夷山主景区 2015 年累计实现门票（含观光车和竹筏票） 2.98 亿元 ${ }^{[30]}$ 。 平均支付意愿在不同因素下具有组间差异（表 5)，主要表现为男性、青年、高学历 者、西部地区游客、高收人者、对保护地有了解有参与的游客支付意愿更强。

通过对受访者人口学特征和保护认知与支付意愿选择的卡方检验发现，性别、教育 水平、客源地、职业、保护意识预判对免门票的替代支付意愿没有显著影响。年龄和个

表 5 个人属性和支付意愿

Table 5 The WTP based on the demographic characteristics of the interviewees

\begin{tabular}{|c|c|c|c|c|}
\hline \multirow{2}{*}{ 项目 } & \multirow{2}{*}{ 属性 } & \multicolumn{2}{|c|}{ 愿意支付 } & \multirow{2}{*}{$W T P /$ 元 } \\
\hline & & 组内比例 $/ \%$ & 组间比例/\% & \\
\hline \multirow[t]{2}{*}{ 性别 } & 男 & 90.6 & 44.1 & 172.3 \\
\hline & 女 & 90.6 & 46.4 & 157.5 \\
\hline \multirow[t]{5}{*}{ 年龄 } & $<18$ 岁 & 90.3 & 11.9 & 181.4 \\
\hline & 18 25岁 & 91.3 & 18.5 & 153.6 \\
\hline & 25 40 岁 & 89.2 & 31.4 & 176.7 \\
\hline & 40 60岁 & 93.6 & 26.1 & 156.6 \\
\hline & $>60$ 岁 & 76.9 & 2.5 & 105.8 \\
\hline \multirow[t]{5}{*}{ 教育水平 } & 小学及以下 & 81.2 & 3.3 & 149.2 \\
\hline & 初中 & 82.9 & 8.6 & 133.2 \\
\hline & 高中 & 88.2 & 19.0 & 158.5 \\
\hline & 大学 & 93.6 & 52.0 & 171.5 \\
\hline & 研究生及以上 & 90.9 & 7.6 & 181.8 \\
\hline \multirow[t]{3}{*}{ 地区 } & 东部 & 91.5 & 65.5 & 159.3 \\
\hline & 中部 & 84.7 & 12.7 & 169.2 \\
\hline & 西部 & 93.4 & 10.9 & 193.2 \\
\hline \multirow[t]{10}{*}{ 职业 } & 政府工作人员 & 96.0 & 6.1 & 151.0 \\
\hline & 企业管理人员 & 97.5 & 9.9 & 202.5 \\
\hline & 工程师/教师/医疗人员 & 92.6 & 22.1 & 170.3 \\
\hline & 服务、销售人员 & 83.8 & 7.9 & 128.0 \\
\hline & 工人 & 81.8 & 2.3 & 118.2 \\
\hline & 农民 & 60.0 & 0.8 & 82.5 \\
\hline & 学生 & 93.3 & 24.9 & 171.8 \\
\hline & 离退休人员 & 83.3 & 2.5 & 142.7 \\
\hline & 个体户 & 91.7 & 5.6 & 218.2 \\
\hline & 其他 & 82.5 & 8.4 & 136.3 \\
\hline \multirow[t]{4}{*}{ 个人年收人 } & $<1$ 万元 & 91.7 & 30.7 & 167.7 \\
\hline & 1 万 5 万元 & 85.8 & 24.4 & 136.0 \\
\hline & 5 万 10 万元 & 95.9 & 23.4 & 181.4 \\
\hline & >10万元 & 89.0 & 12.2 & 187.0 \\
\hline \multirow[t]{2}{*}{ 环保志愿者 } & 是 & 93.3 & 39.0 & 169.5 \\
\hline & 否 & 88.6 & 51.2 & 161.2 \\
\hline \multirow[t]{2}{*}{ 了解国家公园 } & 是 & 91.4 & 62.2 & 170.6 \\
\hline & 否 & 88.9 & 28.4 & 152.1 \\
\hline
\end{tabular}


人收人的影响接近显著 $(P=0.083,0.064)$ 。支付意愿在年龄组间呈现先增加再减少的趋 势, 在 $25 \sim 40$ 岁这一阶段为最高, 是 60 岁以上人群的 1.5 倍; 该组人群教育水平高, 大学 以上学历占总样本量的 $26.6 \%$ 。支付意愿在年收人组间总体呈增加趋势，组间差距达到 1.44 倍，但最低收人群体的支付意愿并不是最低的。

支付意愿影响因素的多重对应分析可以显示因素间以及因素与支付意愿的关系紧密 程度。初步研究发现, 人口统计因子中的性别、客源地, 以及保护意识预判在任何一个维 度上都与其他变量没有明显关系，因此，在最终分析中去除。结果显示（图2), 两维因 子分别包含了 $56.9 \%$ 和 $40.7 \%$ 的信息量，总计 $97.6 \%$ 。在下文分析中括号内数字代表所分 析的因素（个人属性与支付意愿）的组别序号，其中 60 岁以上退休人群信息没有分析。

从人口统计因素来看，年龄信 息主要体现在第一维度上, 25 岁上 下的区分 $(3,4 ; 1,2)$ 在 $Y$ 轴左右 比较明显; 教育和收人信息则在两 个维度都有所体现, 职业信息主要 在第二维度上。各因素之间呈现出 一些明显的聚合关系：

最低收人人群（1）明显与最低 学历（1）、低龄（1）以及学生群体 聚合（7）(第一象限); 较低收人人 群（2）在年龄、学历上没有明显的 关联，但是从事职业集中在服务业 从业人员（4）、农民（6）和个体户 (10) 等 (第三象限); 中等收人人 群（3）年龄上集中于 25 60 岁（3, 4), 学历多在大学以上 (4), 职业 上中等收人以较为稳定的政府工作 人员（1）、工程师（3）等专业技术

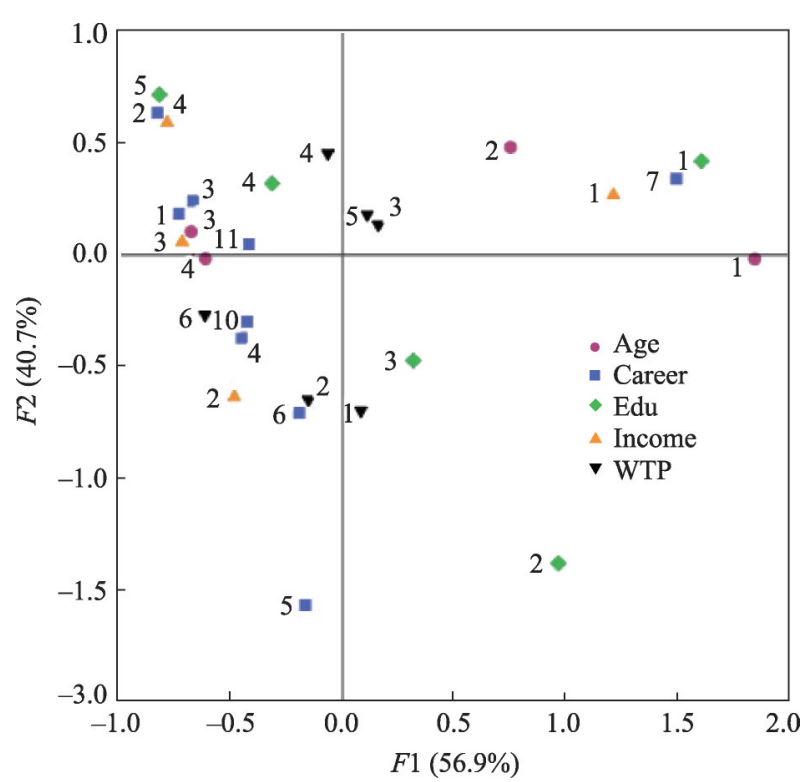

注：因素分类编号顺序依照表 1 及表 4 所示。

图 2 支付意愿及人口统计因素的多重对应分析 Fig. 2 MCA of WTP and demographic factors 人员为主 (第二象限), 而最高收人

(4) 的学历也最高 (5), 从事职业主要是企业管理人员（2）等（第二象限）。

从以上分析看出, 低收人和高收人人群的学历、年龄和职业特征明显; 而支付意愿 在第一维度上区分度不是很高, 表现为在以上因素相对极端的人群里差异不大; 支付意 愿主要是跟教育程度在第二维度上正相关; 同时跟职业关系也相对紧密, 表现为农业 (6) 等从业人员支付意愿相对较低 $(1,2)$, 而政府工作人员/专业技术人员 $(1,3)$ 等 的支付意愿相对较高 $(3,4,5)$ 。

最优尺度回归分析（表 6）进一步验证了职业和教育水平对支付意愿的显著影响, 其次是年龄和客源地; 从重要性分析, 个人年收人的影响也比较大。最优尺度转换可以 通过标准化后的评分对原始因变量进行重新分类以显示因素的不同组别对因变量的影响 差异：五组年龄的量化评分在 18 25 岁和 25 40 岁两个区间是一样的，而 18 岁以下和 60 岁以上则非常不同，所以年龄对支付意愿的实际影响可以认为发生在四组间; 五组教育 
表 6 支付意愿影响因素的最优尺度回归分析

Table 6 Optimal scaling regression analysis of the factors affecting WTP

\begin{tabular}{|c|c|c|c|c|c|}
\hline 变量 & 性质 & 重要性 & 回归系数 & $F$ 值 & $P$ 值 \\
\hline 是否知道国家公园 & 名义变量 & -0.014 & 0.037 & 0.902 & 0.343 \\
\hline 性别 & 名义变量 & 0.010 & 0.021 & 0.262 & 0.609 \\
\hline 年龄 & 有序变量 & 0.172 & -0.186 & 3.404 & $0.018^{*}$ \\
\hline 教育水平 & 有序变量 & 0.352 & 0.249 & 7.213 & $0.000^{* *}$ \\
\hline 地区 & 名义变量 & 0.090 & 0.098 & 3.628 & $0.028^{*}$ \\
\hline 个人年收人 & 有序变量 & 0.137 & 0.148 & 2.175 & 0.141 \\
\hline 是否参加过环保志愿活动 & 名义变量 & 0.038 & 0.064 & 2.085 & 0.150 \\
\hline 职业 ～～～～～～～～～～ & 名义变量 & 0.215 & 0.223 & 9.377 & $0.000^{* *}$ \\
\hline
\end{tabular}

注: “"*分别表示在 $10 \% 、 5 \%$ 水平下差异显著。

水平中初中以下两组的评分基本相同，它们对支付意愿的影响较为一致，则教育的影响 可以认为发生在四组间; 四组收人的尺度转化可以将影响归并为低收人/中等收人，较高 收人/高收人两组; 而三组地区的影响差异主要体现在西部与中东部间。

\section{3 结论与讨论}

\section{1 结论}

通过引人生态系统服务研究框架，对武夷山国家公园试点区生态系统服务关键受益 人之一的游客进行了生态系统服务的社会选择和保障这些服务持续的支付意愿的调查。 主要结果如下:

游客对于生态系统服务的选择格外关注森林生态系统的空气净化调节功能和文化服 务功能, 包括生态旅游、环境教育、本土文化和美学价值, 在具体项目的选择上存在协 同和权衡。权衡主要表现为对生态旅游不同形式基于活动强度而有不同选择，协同主要 表现为对茶文化的需求与环境教育的参与体现形式同时出现。同时，这些具有最高需求 的生态系统服务供给都局限于武夷山本身，而游客需求地广至全国。

在体现公益性的免门票假设下，调查民众愿意支付比例达到 $90 \%$ 以上，但是平均支 付意愿没有达到现有门票价格。教育水平、职业、年龄和个人收人是相对重要的影响因 素，也共同形成了特征人群。研究也表明，平均支付意愿较高的人群相对而言或者缺乏 实际支付能力，或者不占大众旅游群体多数。

因此，在武夷山国家公园体制试点建设中，在满足游客群体的生态系统服务需求 上, 需要完善生态系统管理职能的空间覆盖面, 解决生态系统服务供需空间尺度错位; 需要界定文化服务中各类服务和产品的商品属性和供给方式, 保障公共产品的公益属 性。同时, 也需要自上而下积极推进国家公园概念、定位和功能的大众宣传普及, 从建 设初期就开展社会参与, 从根本上提高受益者对生态系统的认知, 从受益者需求人手推 进国家公园公益性功能实现。

\section{2 生态系统服务的社会选择对国家公园管理的启示}

研究结果表明，游客看重全方位直接体验国家公园自然、景观和文化，文化服务需 求高; 对森林生态系统净化空气这一调节服务的重视, 反映出除了高层次的文化和精神 
享受，基本的健康诉求也成为出行的重要原因，这类似于国家公园概念在 19 世纪末从美 国向澳大利亚传播时提倡工业化下的人们逃离城市去 “享受纯净空气” ${ }^{[31]}$ 。

对游客生态系统服务需求的多重对应分析体现了游客对不同生态旅游方式在选择上 的协同和权衡: 看重竹筏体验的人群, 对徒步也有需求, 但对自然观察和森林疗养这样 趋静的活动需求少, 其选择差异源自生态旅游不同形式的强度差异; 以亲身参与互动的 方法学习体验与对茶文化的需求同时出现, 反映了传统文化作为重要的本土知识吸引游 客体验和学习; 观景需求与其他生态服务没有直接的竞争关系。

这些社会选择特征对武夷山国家公园试点区为游客提供生态系统服务提出了三个方 面的挑战:

（1）森林的净化空气功能由于游客进人森林来感受清洁空气的需求，可能会从一种 纯粹的公共产品变得具有竞争性, 从而不能无限制地供所有人享受。

(2) 游客对本土文化和美学价值同时具有强烈需求, 而武夷山具有我国遗产地文化 与自然景观相关联的典型特征 ${ }^{[32]}$, 使得将附着在自然之上的文化特性纳人国家公园管理 成为必要, 如怎样规范茶山管理来促进这一文化景观与森林生态系统相适应。

（3）游客多样化的文化服务需求，为界定各类产品和服务的属性从而明确向供给方 提出挑战。例如，竹筏目前是由风景名胜区下属股份有限公司运营; 自然观察项目现在 尚未提供。

针对这些挑战，武夷山国家公园体制试点区需要从生态系统服务的商品属性以及供 需匹配人手来进行管理。从商品属性看, 国家公园必须对具有公共产品性质的生态服务 质量进行监督, 以应对可能出现的竞争。对于已经提供或者存在需求而尚未提供的包括 游览、体验、教育等服务, 需要界定这些服务的商品属性, 确定合适的供给方, 如引人 特许经营等。研究发现在国家公园试点建设时期, 游客对其功能还不明确, 尽管在调查 中对于国家公园的管理目标进行了明确说明，但从游客对生态服务的评估可以看到，对 本土文化的需求集中在茶文化，对环境教育的需求集中在参与式活动。因此，也应当注 意如何提高宗教、考古和农业文化在游客群体中的认知度，完善通过印刷物、博物馆和 环境解说来形成环境教育, 使武夷山从一个旅游目的地转变为可以提供全面的游惒体验 和环境教育的国家公园，突出自然生态与文化的长期互动价值。

从提高供需匹配看，在空间上不同类型的生态服务效益存在一定空间流向和辐射范 围。竹筏游览、自然观察、徒步、森林疗养等的供给空间在国家公园试点区内，而需求 空间可以延伸至东南亚。这种文化服务的供给一需求流向的特殊性可以引起生态服务供 给一需求的空间不匹配 ${ }^{[33]}$ 。从客源地空间差异看, 非大陆游客更为看重本土文化和环境 教育, 西部游客重视气候调节。值得一提的是, 环境教育中的环境解可以为国家疆域内 不同个体在进人这个供给空间时提供认同感 ${ }^{[3]}$, 对国家疆域外的不同个体提供到访地的 重要意义 ${ }^{[3]}$ 。所以，武夷山国家公园试点区应当成为民族身份构建、宣传和大众接受的主 要贡献者 ${ }^{[35]}$ 。因此, 武夷山国家公园试点区管理需要去考量这些辐射范围限于局地的生 态服务供应热点区域在哪里，需求者的空间分布如何，管理机制应当以何种尺度适应生 态系统服务的空间尺度。例如，是应当将管理机构和决策尺度放在关键的生态系统服务 热点地区, 还是需要机构能够协调主要游客来源地来缓解需求压力? 是否能够促进辐射 范围更为广泛的生态服务的流动, 比如对于美学价值、文化价值以多媒体、印刷出版等 
传递途径来到达遥远的人群。目前, 在大多数研究都关注生态系统服务热点区时, 考虑 从需求方解决生态系统管理可以是未来国家公园试点区的一个方向。

\section{3 游客支付意愿揭示的国家公园公益性实现的辅助机制}

从游客对生态系统服务的选择中可以看出受到重视的需求很多是经济学意义上的公 共产品, 其供给是公益性的重要表现; 然而供给地不可移动性使得公共资源长期以来成 为地方经济利益的来源。如何逐步推进国家公园的公益性，建立激励相容的资金机制是

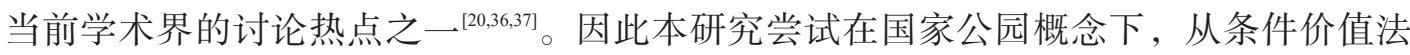
(contingent valuation method, CVM）人手，关注大众作为游客来参与保护公益性的实现。

不少受访者坦言, 门票不可避免, 因为必须要限制人流, 保障环境质量和游㮩体 验; 也有人觉得收取门票给人的强制感不好, 愿意以自愿或变相方式对体验进行支付, 这反应了支付意愿本质上其实是社会选择的体现，而不是经济选择的指标 ${ }^{[38]}$ 。总体而 言, 处于事业发展和成熟期的高学历、高收人人群支付意愿较高, 他们很可能同时也是 收人稳定的政府机构工作人员、专业技术人员，或者是企业管理层或私营业主。他们的 知识面、社会责任感和经济基础等相互交织影响选择。同时, 支付意愿和支付能力并不 一致。处在学习和接受新鲜事物时期的未成年人和学生群体, 生态意识较强, 支付意愿 很高，但实际支付能力可能更多地依附于家庭。我们也发现，来自西部地区的游客明显 表现出更高的支付意愿, 可能是受到西部整体生态环境状况在政策和媒体语境中的频繁 出现，以及他们自己的生活记忆影响。

这一结果显示民众有参与生态保护的意愿和潜力, 但是需要对参与方式进行区分, 可能不限于单一的替代支付。研究结果也表明一个潜在的矛盾, 相对而言, 高学历、高 收人、事业较为成熟的人群对国家公园的管理目标和通过社会参与推进公益性实现的逻 辑关系更容易理解和实践, 然而目前的景区仍然以吸引大众游客为主, 整个调查群体半 数以上从来都没有参与过环境保护类的志愿活动, 三分之一多完全不知道什么是国家公 园。从这个意义上来说, 自上而下的推进国家公园试点区建设不仅要关注其生态系统服 务供给区的生物多样性等生态系统本底价值, 而且要主动引导生态系统服务需求方对这 个供应链进行理解, 提高整个需求方的生态认知, 从而提高他们参与保护的可能性, 建 立多样化的游客参与保护的机制, 包括替代支付、志愿活动、品牌产品购买等。当然, 国家公园公益性的实现不仅要靠游客, 也要考虑人们在游客身份之外以何种方式和手段 参与保护，以及如何联动保护地社区居民与游客等外来群体建立保护管理的互动。

致谢: 感谢来自同济大学、南京大学、北京师范大学、中国人民大学、山东师范大学、 中国海洋大学、云南大学、世界自然基金会（瑞士）北京代表处的志愿者; 感谢武夷山 国家级风景名胜区管委会、旅游局、发展改革和科技局的帮助和支持。

\section{参考文献(References):}

[1] FROST W, HALL M. Tourism and National Parks: International Perspectives on Development, Histories and Change. London: Routledge, 2009: 30-44.

[2] ROSENBERG A A, MCLEOD K L. Implementing ecosystem-based approaches to management for the conservation of ecosystem services. Marine Ecology Progress Series, 2005, 300: 270-274.

[3] RUNTE A. Reply to Sellars. Journal of Forest History, 1983, 27(3): 135-141.

[4] COLE D N, LANDRES P B. Threats to wilderness ecosystems: Impacts and research needs. Ecological Applications, 
1996, 6: 168-184.

[5] GÖSSLING S. Ecotourism: A means to safeguard biodiversity and ecosystem functions?. Ecological Economics, 1999, 29(2): 303-320

[6] ZHOU Y, BUESCHING C D, NEWMAN C. et al. Balancing the benefits of ecotourism and development: The effects of visitor trail-use on mammals in a protected area in rapidly developing China. Biological Conservation, 2013, 165: 18-24.

[7] BELTRAME C, COHEN-SHACHAM E, TROUILLET M. et al. Exploring the links between local management and conservation applying the ecosystem services concept: Conservation and tourism service in Camargue, France. International Journal of Biodiversity Science, Ecosystem Services \& Management, 2013, 9: 166-177.

[8] ZODERER B M, TASSER E, ERB K H. et al. Identifying and mapping the tourists perception of cultural ecosystem services: A case study from an Alpine region. Land Use Policy, 2016, 56: 251-261.

[9] ALLENDORF T D, YANG J. The role of ecosystem services in park-people relationships: The case of Gaoligongshan Nature Reserve in Southwest China. Biological Conservation, 2013, 167: 187-193.

[10] LINDEMANN-MATTHIES P, KELLER D, LI X, et al. Attitudes toward forest diversity and forest ecosystem services: A cross-cultural comparison between China and Switzerland. Journal of Plant Ecology, 2014, 7(1): 1-9.

[11] PAN Y, MARSHALL S, MALTBY L. Prioritising ecosystem services in Chinese rural and urban communities. Ecosystem Services, 2016, 21: 1-5.

[12] WEI J. Ecosystem services research in China: A critical review. Ecosystem Services, 2017, 26: 10-16.

[13] BARAL H, KEENAN R J, SHARMA S K. Spatial assessment of ecosystem goods and services in complex production landscape: A case study from South-eastern Australia. Ecological Complexity, 2014, 13: 35-45.

[14] DAW T M, COULTHARD S, CHEUNG W W L, et al. Evaluating taboo trade-off in ecosystems services and human well-being. PNAS, 2015, 112: 6949-6954.

[15] MAES J, PARACCHINI M L, ZULIAN G. Synergies and trade-offs between ecosystem services supply, biodiversity, and habitat conservation status in Europe. Biological Conservation, 2012, 155: 1-12.

[16] XU J C, MELICK D R. Rethinking the effectiveness of public protected areas in Southwestern China. Conservation Biology, 2007, 21(2): 318-328.

[17] 汪德根, ALAN A L. 国家公园“门票经济”的公益性回归与管理体制改革. 旅游学刊, 2015, 30(5): 11-13. [WANG D G, ALAN A L. The return of public benefit in ticket economy of national park and the reform of management system. Tourism Tribune, 2015, 30(5): 11-13.]

[18] HAN F, YANG Z P, WANG H, et al. Estimating willingness to pay for environment conservation: A contingent valuation study of Kanas Nature Reserve, Xinjiang, China. Environmental Monitoring and Assessment, 2011, 180: 451-459.

[19] WANG P W, JIA J B. Tourists' willingness to pay for biodiversity conservation and environment protection, Dalai Lake protected area: Implications for entrance fee and sustainable management. Ocean \& Coastal Management, 2012, 62: 2433.

[20] 许丽忠, 张江山, 王菲凤, 等. 熵权多目的地 TCM 模型及其在游憩资源旅游价值评估中的应用: 以武夷山景区为例. 自然资源学报, 2007, 22(1): 28-36. [XU L Z, ZHANG J S, WANG F F, et al. Principles and application of using entropy-weight-based multiple-destination Travel Cost Method to evaluate the tourism value of recreation resources: A case study of Wuyishan. Journal of Natural Resources, 2007, 22(1): 28-36.]

[21] 王英姿, 何东进, 洪伟, 等. 武夷山风景名胜区森林生态系统公共服务功能评估. 江西农业大学学报, 2006, 28(3): 409-414. [WANG Y Z, HE D J, HONG W, et al. Evaluation of forest ecosystem services of Wuyishan scenery district. Acta Agriculturae Universitatis Jiangxiensis, 2006, 28(3): 409-414.]

[22] 王洪翠, 吴承祯, 洪伟, 等. 武夷山风景名胜区生态系统服务价值评价. 安全与环境学报, 2006, 6(2): 53-56. [WANG H C, WU C Z, HONG W, et al. Estimation for value of ecosystem services in Wuyishan Scenery District. Journal of Safety and Environment, 2006, 6(2): 53-56.]

[23] 许纪泉, 钟全林. 武夷山自然保护区森林生态系统服务功能价值评估. 林业资源管理, 2007, (3): 77-81. [XU J Q, ZHONG Q L. Evaluation of the forest ecosystem service functions for tourism in Wuyi Mountains. Forest Resources Management, 2007, (3): 77-81.] 
[24] 武夷山国家公园体制试点区试点实施方案, 2016. [Implementation Plan of the Wuyishan National Park Pilot, 2016.]

[25] 武夷山市旅游局. 武夷山市2015年1-12月份旅游经济运行情况分析. (2016年 10月). 2016-01-11. http://www.wuyishan.gov.cn/Articles/20160426/20160426111425351.html. [The Tourism Bureau of Wuyishan. Analysis of tourism economy in Wuyishan in 1-12 of 2015. (Oct. 2016). 2016-01-11.]

[26] 武夷山风景名胜区管理委员会. 武夷山风景名胜区管理委员会 2015 年财务预算. (2016年10月 ). 2015-11-17. http: //www.whwy.org/News/Info.asp?infoid=1468. [Management Committee of the Wuyishan Scenic Area. Financial budget for 2015. (Oct. 2016). 2015-11-17.]

[27] COSTANZA R, DE GROOT R, SUTTON P, et al. Changes in the global value of ecosystem services. Global Environmental Change, 2014, (26): 152-158.

[28] GARCÍA-NIETOA A P, GARCÍA-LLORENTEA M, INIESTA-ARANDIAA I, et al. Mapping forest ecosystem services: From providing units to beneficiaries. Ecosystem Services, 2013, 4: 126-138.

[29] 石玲, 马炜, 孙玉军, 等. 基于游客支付意愿的生态补偿经济价值评估: 以武汉素山寺国家森林公园为例. 长江流域 资源与环境, 2014, 23(2): 180-188. [SHI L, MA W, SUN Y J, et al. Economic evaluation of eco-compensation based on tourists' willingness-to-pay: A case study of Sushansi national forest park, Wuhan, China. Resources and Environment in the Yangtze Basin, 2014, 23(2):180-188.]

[30] 福建新闻网. 武夷山去年旅游门票收人近 3 亿. (2016年 10 月). 2016-03-24. http://www.fj.chinanews.com/news/2016/ 2016-03-24/339321.shtml. [Fujian News: 300 million income from Wuyishan last year (Oct 2016).]

[31] Queensland, Official records of the debates of the Legislative Council Legislative Assembly. 1906, 98: 1514.

[32] 陈耀华. 中国自然文化遗产的价值体系及其保护利用. 北京: 北京大学出版社, 2014. [CHEN Y H. The Value System and Its Protection and Utilization of Natural and Cultural Heritage in China. Beijing: Peking University Press, 2014.]

[33] DE GROOT R S, ALKEMADE R, BRAAT L, et al. Challenges in integrating the concept of ecosystem services and values in landscape planning, management and decision-making. Ecological Complexity, 2010, 7: 260-272.

[34] HOWARD P. Heritage: Management, Interpretation, Identit. London and New York: Continuum, 2003.

[35] WALL G. Outdoor recreation and the Canadian identity, in WALL G. and MARSH J. (eds.) Recreational Land Use: Perspectives on its Evolution in Canada. Ottawa: University of Carlton Press, 1984: 418-434.

[36] 李俊生,朱彦鹏. 国家公园资金保障机制探讨. 环境保护, 2015, 43(14): 38-40. [LI J S, ZHU Y P. Discussion on national park funds safeguard mechanism. Environmental Protection, 2015, 43(14): 38-40.]

[37] 陈耀华, 黄丹, 颜思琦. 论国家公园的公益性、国家主导性和科学性. 地理科学, 2014, 34(3): 257-264. [CHEN Y H, HUANG D, YAN S Q. Discussions on public welfare, state dominance and scientificity of national park. Scientia Geographica Sinica, 2014, 34(3): 257-264.]

[38] CASTRO A J, MARTÍN-LÓPEZC B, GARCÍA-LLORENTEC M, et al. Social preferences regarding the delivery of ecosystem services in a semiarid Mediterranean region. Journal of Arid Environments, 2011, 75: 1201-1208. 


\title{
Realisation of recreation in national parks: A perspective of ecosystem services demand and willingness to pay of tourists in Wuyishan Pilot
}

\author{
HE Si-yuan', SU Yang ${ }^{2}$, WANG Lei ${ }^{3}$, CHENG Hong-guang ${ }^{4}$ \\ (1. Institute of Geographic Sciences and Natural Resources Research, CAS, Beijing 100101, China; \\ 2. Development Research Center of the State Council, Beijing 100013, China; \\ 3. World Wide Fund For Nature Beijing Office, Beijing 100037, China; \\ 4. School of Environment, Beijing Normal University, Beijing 100875, China)
}

\begin{abstract}
China's national parks aim to promote conservation and improve public welfare. This research took tourists as one of the key ecosystem services beneficiaries. It used an ecosystem services approach to identify social perceptions and willingness to pay regarding different ecosystem services in the Wusyishan National Park Pilot, in order to find ways to optimise tourism to promote conservation and to improve public welfare in the establishment of the national park system. A social survey was conducted using questionaires focusing on the assessment of the importance of ecosystem services and the willingness to pay, and the data were analysed using weighted scoring, multiple correspondence analysis and optimal scaling regression. Results showed that most respondents recognised the importance of various cultural services, including eco- tourism which is high in practicality, activities to have cultural experience which is rather abstract and enjoying the beautiful scenery; however, there were trade-offs among specific ecosystem services. Tourists thought highly of maintaining air quality and it was the only regulating service that ranked the top five. In addition, they did not choose any provisioning services among the top five important ecosystem services. Under the entry tickets fee waiver hypothesis, more than $90 \%$ respondents were willing to pay for maintainance of the ecosystem services, but the average payment of 165.9 yuan/person was less than current ticket price. Willingness to pay was significantly affected by education level and career; together with the impact of age and personal income, clustered groups with certain willingness to pay were identified. These findings indicate that in the development of tourism in national parks, managers should focus on securing typical cultural ecosystem services regarding tradeoffs in demand from different tourist groups. They also should improve the public's awareness of the chracteristics of ecosystems to facilitate their active participation in conservation.
\end{abstract}

Keywords: national park; ecosystem services; willingness to pay; Wusyishan 